\title{
Frequency of Hemiplegic Shoulder Pain after 3 Months of Stroke in Lahore
}

\author{
Ramsha Aslam $^{1}$, Gulnaz Zaheer ${ }^{2}$, Hafiz Sheraz Arshad ${ }^{3}$ \\ ${ }^{1}$ Physiotherapist, Azra Naheed Medical College, Department of Physical Therapy, Main Raiwind Road, Lahore \\ ${ }^{2}$ Lecturer, Azra Naheed Medical College, Department of Physical Therapy, Main Raiwind Road, Lahore \\ ${ }^{3}$ Assistant Professor, Azra Naheed Medical College, Department of Physical Therapy, Main Raiwind Road, Lahore
}

\begin{abstract}
Painful shoulder is a communal and possibly impairment disorder disturbing stroke stayers. Utmost current figures recommend nearly one-third of individuals involved in hemiplegic shoulder pain in the first 4 months post stroke. The objective of study was to determine the frequency of shoulder pain in the hemiplegic patients after 3 months of stroke. This cross sectional observational study comprised 132 stroke patients. Frequency tables were used to found out the frequency of hemiplegic pain in stroke patients. The finding of this study indicate that the Occurrence of hemiplegic shoulder pain is common problem in stroke patients and Frequency of hemiplegic pain in stroke patients is very high which leads to immobilization and cause muscle atrophy.
\end{abstract}

Keywords: Hemiplegic Shoulder Pain, Stroke, Cerebrovascular Accident, Shoulder, Rehabilitation Centers

\section{Introduction}

\subsection{Overview}

Stroke is usually considered as a nervous insufficiency recognized to an severe focal damage of the central nervous system by a vascular source, with intracranial hemorrhage, subarachnoid hemorrhage, and intracranial; cerebral infraction in addition remains a chief reason of death and disability in all over the world. The recent World Health Organization explanation of stroke (announced in 1970 and static used) is "quickly rising sign and symptoms of global and focal disruption of intellectual function, long-lasting more than one day and cause mortality, by vascular origin.(1)

Cases of first-ever cerebrovascular accident followed universal incidence is 16.9 million in 2010 or the figure of individuals alive post stroke was expected at 33 million.(2)

Longstanding abnormalities, such as hemiparesis, verbal difficulties and cerebral deficits is cause by stroke and third foremost cause of death in the built-up world.(3)

Prolonged pain in the hemiplegic shoulder is a common magnitude of hemiplegic due to intellectual vascular injuries, occurs among 21 to 84 percent of stroke patients in two-three months of post stroke. Spasticity and adhesive capsulitis are communal in hemiplegic painful shoulder.(4)

The pathology of hemiplegic shoulder pain is not wellknown and furthermost researchers rely on that numerous aspects add to hemiplegic pain. The related features of hemiplegic shoulder pain comprise deprived upper limb movement, rise muscle tone on shoulder, shoulder subluxation, shoulder restriction, rotator cuff lesions, and reflex sympathetic dystrophy.(5)

Pain of shoulder is problematic condition of post stroke, in $70 \%$ of cases round about incidence of post stroke shoulder pain is inconstant and it frequently seems in the first starting days of stroke and in the first year succeeding a stroke $75 \%$ of patients felt pain sensation at certain interval. The Bio machines meant for the progression of pain sensation are occasionally indistinguishable anyhow, ever since the muscular connection of the superior limb to the trunk followed than straight skeletal, each biomechanical problem of shoulder cause disturbance of muscular work, which can main cause of discomfort. Reduced shoulder elevation power, abnormal muscle tone and reduced pinch grip linked with pain of shoulder but furthermost significantly, by sensual negligence and sensory injury.(6) Major complication of after stroke is hemiplegic painful shoulder. Its arrival carries pain and restrict active daily living activities and limit contribution in particular neurologicaltraining educational programs. This indications leads to decrease quality of practical work prognosis. Better supervision of stroke patients be able to lessen equally the incidence and amount of shoulder pain, refining purposeful result(7). Advancement of a hemiplegic painful shoulder complex complication and extends restoration, rises the interval of stay in hospital, can outcome in reduced upper limb task twelve weeks post stroke. Constraint-induced programed rehabilitation is a sample of method that includes repetition functional training that was established openly start from simple knowledge of science literature, And in the hemiparetic limb constraint induced therapy provides opportunity for enhancement of functional level.(8)

\subsection{Objectives}

The objective of this study to determine the frequency of shoulder pain in the hemiplegic patients after 3 months of stroke in rehabilitation centers.

\subsection{Rationale}

Through frequency of shoulder pain we can find out those risk factors that cause increase shoulder pain in stroke as a 


\section{International Journal of Science and Research (IJSR) \\ ISSN (Online): 2319-7064}

Index Copernicus Value (2013): 6.14 | Impact Factor (2015): 6.391

result it will be improving the quality of life of those suffering from hemiplegic shoulder pain after stroke.

\subsection{Operational Definitions}

\subsubsection{VAS}

The pain (VAS) visual analogue scale is a one-dimensional measure of pain intensity, which has been broadly used in various adult populations. For pain intensity, the scale is most generally anchored by "no pain" score of 0 and "pain as bad as it could be" or "worst imaginable pain" score of 100 (100-mm scale).(9) Visual analog scales have been extensively used for valuation in a number of health fields for example acute and chronic pain.(10)

\subsubsection{Reliability}

Test-retest reliability has been shown to be good, but higher among literate $(\mathrm{r}=0.94, P<0.001)$ than illiterate patients $(\mathrm{r}$ $=0.71, P<0.001)$.(9)

\subsubsection{Validity}

Validity with correlation between vertical and horizontal orientations of the VAS is 0.99. (Hawker et al., 2011).(9)

\subsection{Materials and Methods}

\subsubsection{Study Design}

The present study is a cross-sectional observational study

\subsubsection{Setting}

The study was conducted in four different rehabilitation centers of Lahore

\subsubsection{Study Population}

Male and female stroke patients of Mayo, Jinnah, General, Sheikh Zaid Hospitals of rehabilitation centers.

\subsubsection{Duration of Study}

The study took 3 months after approval from advance research committee

\subsubsection{Sample size}

One hundred and thirty two individual participate in the study was admitted at 4 different hospitals of Lahore who was be agree to take part in the study. In circumstances in which patients will incapable to brief current condition, the calculation will be done on defense of the patient by their responsible person established by way of a trustworthy method of supervision. In this study sample size is excluded by rosoft. The sample size $\mathrm{n}$ and border of error $\mathrm{E}$ are assumed by this formula

$$
\begin{aligned}
& =\mathrm{Z}(\mathrm{c} / 100) 2 \mathrm{r}(100-\mathrm{r}) \\
& =\mathrm{N} \mathrm{x} /((\mathrm{N}-1) \mathrm{E} 2+\mathrm{x}) \\
& =\mathrm{Sqrt}[(\mathrm{N}-\mathrm{n}) \mathrm{x} / \mathrm{n}(\mathrm{N}-1)]
\end{aligned}
$$

Where $\mathrm{N}$ is the populace size, $\mathrm{r}$ is the fraction of answers that you are concerned in, and $Z(c / 100)$ is the critical value for the confidence level c.

\subsubsection{Eligibility}

\subsubsection{Inclusion Criteria}

- Patient has stroke with hemiplegia will be include
- months of post stroke

- 40-70 years

- Both male and female patient

\subsubsection{Exclusion Criteria}

- Intellectually ill \& mentally unstablepatient.

- Shoulder pain due to RTA, fall and other pathologies

- Patients have any systemic illness, tumors, infections and pregnant females

\subsubsection{Data collection}

The study was conducted in rehabilitation centers which has about 132 stroke patients enrolled in physiotherapy centers of Mayo hospital, General hospital, Jinnah hospital and Sheikh Zaid hospital at Lahoreat the start of study. All stroke patients were available during study duration in which 14 stroke patients had no pain and 118 stroke patients had hemiplegic shoulder pain. Stroke patients were selected by simple convenient sampling technique. . Data were collected by visual analog pain scale were used to measure hemiplegic shoulder pain in stroke patient.

\subsubsection{Ethical consideration}

The ethical committee and rehabilitation centers approved to conduct the study in hospitals of physiotherapy units' only those stroke patients were involved in the study who contracted the written consent form. All the private data of patients were retained concealed

\subsubsection{Statistical Procedure}

The Data was analyzed using SPSS softwere16 version program and presenting in the form of frequency tables and the outcome taken in Microsoft Excel and calculated as percentages. For the data evaluation,Frequency table test was used

\section{Results}

\subsection{Socio-demographic Profile}

Socio-demographic Profile of patients

Table 1: Age

\begin{tabular}{|l|l|l|l|}
\hline Sr \# & Variable & Frequency & percentage \\
\hline 1 & $40-50$ & 35 & 26.5 \\
\hline 2 & $51-60$ & 38 & 28.8 \\
\hline 3 & $61-70$ & 59 & 44.7 \\
\hline
\end{tabular}

In this study 300 subjects were enrolled, Out of 132 patients of stroke, majority of patients enrolled between the age of $61-70$ were $59(44.7 \%)$, remaining patients enrolled between the age of 51-60 were $38(28.8 \%)$ and $40-50$ were $35(26.5 \%)$.

Table 1: Gender

\begin{tabular}{|c|c|c|c|}
\hline Sr \# & Variable & Frequency & percentage \\
\hline 1 & Male & 78 & 59.1 \\
\hline 2 & Female & 54 & 40.9 \\
\hline
\end{tabular}

Out of 132 patients of stroke, 78 are male with $59.1 \%$ and 54 are female with $40.9 \%$ 


\section{International Journal of Science and Research (IJSR) \\ ISSN (Online): 2319-7064}

Index Copernicus Value (2013): 6.14 | Impact Factor (2015): 6.391

Table 2: Status

\begin{tabular}{|c|c|c|c|}
\hline Sr \# & variable & frequency & percentage \\
\hline 1 & Upper & 2 & 1.5 \\
\hline 2 & Middle & 50 & 37.9 \\
\hline 3 & Lower & 80 & 60.6 \\
\hline
\end{tabular}

Out of 132 patients of stroke, majority of patients $80(60.6 \%)$ belong to lower class, $50(37.9 \%)$ belongs to middle class and $2(1.5 \%)$ belongs to lower class.

Table 4: Hospital

\begin{tabular}{|c|c|c|c|}
\hline Sr \# & Variabl & Frequency & Percentage \\
\hline 1 & Jinnah & 23 & 17.4 \\
\hline 2 & Mayo & 53 & 40.2 \\
\hline 3 & General & 27 & 20.5 \\
\hline 4 & Sheikh Zaid & 29 & 22.0 \\
\hline
\end{tabular}

Out of 132 patients of stroke, majority of the patients 53(40.2) belongs to mayo hospital, $29(22.0 \%)$ belongs to sheikh Zaid hospital, 27(20.5\%) belongs to general hospital, $23(17.4 \%)$ belongs to Jinnah hospital.

\subsection{Table Hemiplegic Shoulder Pain in Stroke Patients}

Visual Analogue Scale

\begin{tabular}{|c|c|c|c|}
\hline Sr $\#$ & Variable & Frequency & Percentage \\
\hline 1 & No Pain & 14 & 10.6 \\
\hline 2 & Mild & 22 & 16.7 \\
\hline 3 & Moderate & 60 & 45.5 \\
\hline 4 & Severe & 36 & 27.3 \\
\hline
\end{tabular}

Out of 132 patient of stroke, majority of patients 60(45.5) had moderate pain, 36(27.3\%) had severe pain, 22(16.7) had mild pain, 14(10.6) had no pain

\section{Conclusion}

These results designate that shoulder pain is a common problem of post stroke and that it may produce from a variability of aspects. To reduce risk factors and relieve shoulder pain, struggles should be focused to range of motion physical activities, proper placing of the shoulder, and the anticipation of immobilization. Hemiplegic Stroke patients with shoulder pain those look after and receive care in stroke units are more chance to be recover earlier, autonomous, and go to at home one year post stroke. The assistances were most superficial in rehabilitation centers as compare to home care and also had no any systematic problem increases was detected during prolong stay in units.in this study out of 132 patient of stroke, majority of patients had moderate pain which was measure by visual analogue scale

\section{References}

[1] Sacco RL, Kasner SE, Broderick JP, Caplan LR, Culebras A, Elkind MS, et al. An updated definition of stroke for the 21 st century a statement for healthcare professionals from the American Heart Association/American Stroke Association. Stroke. 2013;44(7):2064-89.

[2] Brainin M, Tuomilehto J, Heiss WD, Bornstein NM, Bath P, Teuschl Y, et al. Post-stroke cognitive decline: an update and perspectives for clinical research. European journal of neurology. 2015;22(2):229-e16.

[3] Klit H, Finnerup NB, Overvad K, Andersen G, Jensen TS. Pain following stroke: a population-based follow-up study. PloS one. 2011;6(11):e27607.

[4] Zeilig G, Rivel M, Weingarden H, Gaidoukov E, Defrin R. Hemiplegic shoulder pain: evidence of a neuropathic origin. Pain. 2013;154(2):263-71.

[5] Huang Y-C, Liang P-J, Pong Y-P, Leong C-P, Tseng C$\mathrm{H}$. Physical findings and sonography of hemiplegic shoulder in patients after acute stroke during rehabilitation. Journal of rehabilitation medicine. 2010;42(1):21-6.

[6] Al Masud A. Prevalence of painful shoulder among the hemiplegic patients with cerebrovascular accident (CVA): Department of Physiotherapy, Bangladesh Health Professions Institute, CRP; 2013.

[7] Murie-Fernández M, Iragui MC, Gnanakumar V, Meyer M, Foley N, Teasell R. Painful hemiplegic shoulder in stroke patients: causes and management. Neurología (English Edition). 2012;27(4):234-44.

[8] nderwood J, Clark PC, Blanton S, Aycock DM, Wolf SL. Pain, fatigue, and intensity of practice in people with stroke who are receiving constraint-induced movement therapy. Physical therapy. 2006;86(9):124150.

[9] Hawker GA, Mian S, Kendzerska T, French M. Measures of adult pain: Visual analog scale for pain (vas pain), numeric rating scale for pain (nrs pain), mcgill pain questionnaire (mpq), short-form mcgill pain questionnaire (sf-mpq), chronic pain grade scale (cpgs), short form-36 bodily pain scale (sf-36 bps), and measure of intermittent and constant osteoarthritis pain (icoap). Arthritis care \& research. 2011;63(S11):S240-S52.

[10] Amico KR, Fisher WA, Cornman DH, Shuper PA, Redding CG, Konkle-Parker DJ, et al. Visual analog scale of ART adherence: association with 3-day selfreport and adherence barriers. JAIDS Journal of Acquired Immune Deficiency Syndromes. 2006;42(4):455-

\section{Author Profile}

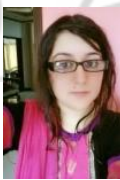

Ramsha Aslam is Doctor of Physical Therapy, Azra Naheed Medical College, Department of Physical Therapy, Main Raiwind Road,Lahore

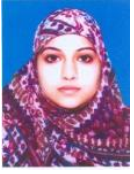

Gulnaz Zaheer is Lecturer, Azra Naheed Medical College, Department of Physical Therapy, Main Raiwind Road, Lahore

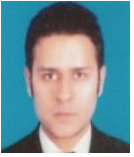

Hafiz Sheraz Arshad is Assistant Professor, Azra Naheed Medical College, Department of Physical Therapy, Main Raiwind Road,Lahore 